\title{
Analisis Forensik Metadata Kamera CCTV Sebagai Alat Bukti Digital
}

\author{
Desti Mualfah ${ }^{1}$, Rizdqi Akbar Ramadhan ${ }^{2}$ \\ ${ }^{1}$ Program Studi Teknik Informatika Fakultas Ilmu Komputer Universitas Muhammadiyah Riau \\ ${ }^{2}$ Program Studi Teknik Informatika Fakultas Teknik Universitas Islam Riau \\ ${ }^{1}$ Jl. Tuanku Tambusai, Pekanbaru, Riau, telp. (0761) 35008 \\ ${ }^{2}$ Jl. Kaharudin Nst No 113, Bukit Raya, Pekanbaru, Riau, telp. (0761) 678267 \\ e-mail: ${ }^{1}$ destimualfah@umri.ac.id, ${ }^{2}$ rizdqiramadhan@eng.uir.ac.id
}

\begin{abstract}
Abstrak
Kejahatan konvensial yang terekam kamera CCTV (Closed Circuit Televison) semakin banyak ditemukan di masyarakat, setiap pelaku kejahatan yang terbukti melakukan tindak pidana tertentu akan dihukum sesuai dengan peraturan perundang-undangan. Kamera CCTV memiliki peran penting dalam keamanan, banyak diantaranya hasil tangkapan rekaman kamera CCTV dijadikan sebagai alat bukti digital. Tantangannya adalah bagaimana teknik yang diperlukan untuk penanganan khusus investigasi digital forensik dalam mencari bukti ditgital rekaman kamera CCTV menggunakan metode live forensik, yaitu ketika barang bukti dalam keadan aktif berdasarkan pedoman SNI 27037:2014 sesuai acuan kerangka kerja Common Phases of Computer Forensics Investigation Models untuk di implementasikan ke dalam dokumen Chain of Custody. Hasil penelitian ini berupa hasil analisis video rekaman kamera CCTV tentang karakteristik bukti digital dan informasi metadata yang digunakan untuk memberikan penjelasan komprehensif secara terstruktur serta acuan pengelolaan informasi data yang didapat dari hasil investigasi digital forensik yang dapat dipertanggungjawabkan dalam persidangan.
\end{abstract}

Kata kunci: Bukti Digital, Live Forensik, Metadata, Kamera CCTV, Chain of Custody.

\begin{abstract}
Conventional crimes that are recorded on CCTV (Closed Circuit Television) cameras are increasingly being found in society, every crime that commits certain crimes will be in accordance with statutory regulations. CCTV cameras have an important role in security, many of which are recorded by CCTV cameras used as digital evidence. The challenge is how the techniques required for special handling, digital forensics in searching for digital evidence of CCTV camera footage using the live forensic method, namely when the evidence is in an active state based on the latest SNI 27037: 2014 according to the framework reference Common Phases of Computer Forensics Investigation Models for in implement it into the Chain of Custody document. These results of this research are in the form of analysis of CCTV camera video recordings about the characteristics of digital evidence and metadata information used to provide a structured comprehensive explanation and reference data management information obtained from the results of digital forensic investigations that can be accounted for in court.
\end{abstract}

Keywords: Digital Evidence, Live Forensic, Metadata, CCTV Camera, Chain of Custady.

\section{Pendahuluan}

Keamanan merupakan salah satu aspek yang harus dijaga dalam kehidupan masyarakat saat ini, semakin meningkatnya kasus kriminal seperti pencurian, perampokan baik dilingkungan rumah, toko maupun perkantoran diperlukan mekanisme untuk meningkatkan keamanan. Berbagai cara dapat dilakukan untuk meningkatkan keamanan, salah satunya dengan memasang kamera pemantau atau yang biasa disebut CCTV (Closed Circuit Televison) yang digunakan sebagai alat kamera pengawas. CCTV terdapat sebuah file rekaman video yang dapat digunakan sebagai alat bukti digital dalam pengungkapan suatu perkara peradilan [1], untuk itu 
diperlukan perlakuan khusus dalam memperoleh rekaman video tersebut agar terjaga keutuhan dan keasliannya [2], untuk menjaga keutuhan dan keaslihan barang bukti di perlukan penerapan ilmu digital forensik dalam investasi kejadian suatu perkara.

Ilmu digital forensik merupakan praktik pembedahan perangkat digital untuk mencari fakta yang diperlukan untuk kepentingan hukum, berbeda dengan ilmu forensik lainnya yang lebih banyak berkaitan dengan pembedahan dan pencarian artefak pada makhluk hidup [3]. Digital forensic memiliki dua kategori alat bukti berupa bukti fisik dan bukti digital. Istilah lain bukti fisik dan bukti digital disebut sebagai bukti elektronik dan bukti digital, dimana alat bukti elektronik memiliki bentuk fisik dan bentuk yang dapat dilihat visual, seperti personal computer, smartphone, kamera, hard disk dan lain-lain [4][5], sedangkan alat bukti berupa digital merupakan alat bukti yang diekstrak atau diperoleh kembali dari alat bukti elektronik bisa berupa file, email, pesan, gambar, video, log maupun teks [6].

Menurut [7], beberapa kasus yang menggunakan kamera CCTV terdapat beberapa asumsi terhadap penggunaan rekaman kamera CCTV yang ditemukan dapat dijadikan sebagai barang bukti atau alat bukti dalam bentuk digital. Merujuk pada Undang-Undang No. 19 Tahun 2016 Pasal 5 Ayat 1 (satu) dan Ayat 2 (dua) tentang informasi dan transaksi elektronik dikatakan bahwa informasi elektronik dan atau dokumen elektronik dan atau hasil cetaknya merupakan alat bukti hukum yang sah, dimana hal tersebut merupakan perluasan dari alat bukti yang sah sesuai dengan Hukum Acara yang berlaku di Indonesia.

Dalam hal ini, kamera CCTV menjadi sebuah alat bukti digital [8] yang valid dan mempunyai sebuah file rekaman yang memberikan sebuah informasi berupa data atau yang biasa dikenal dengan istilah metadata [9], dimana metadata dapat direkam oleh komputer dengan otomatis ketika suatu file dibuat, sehingga dapat diketahui kapan file tersebut dibuat, siapa user pembuatnya, berapa ukuran file nya dan ekstensi yang dihasilkan. Informasi metadata berfungsi untuk menyimpan, menjaga, dan mengelola sumber agar tetap terjaga integritas dan keutuhan file yang di dapat dari kamera CCTV. Selain metadata dalam penanganan barang bukti digital kamera CCTV terdapat hal esensial yang disebut Chain of Custody. Chain of custody merupakan upaya untuk menjaga dan memastikan integritas dalam bukti digital dan prosedur pendokumentasian bukti secara kronologis untuk menjelaskan 5 karakteristik (4W dan $1 \mathrm{H}$ ) Chain of Custody, yaitu fingerprint of evidences (why), digital signing (who), time stamping (when), geo location (where) dan procedures (how) [10].

Selanjutnya, dalam mencari 5 karakteristik Chain of Custody pada rekaman kamera CCTV diperlukan sebuah kerangka kerja Common Phases of Computer Forensics Investigation Models [11] dengan metodologi live forensic [5] dalam mengambil objek komponen dari artefak bukti digital dalam keadaan aktif. Teknik yang diperlukan dalam menganalisis hasil rekaman kamera CCTV, informasi metadata dan Hash suatu file yang terkandung dalam video memerlukan prinsip ilmu digital forensik, karena alat bukti digital pada dasarnya memiliki ciri yang mudah digandakan dan ditransmisi sehingga sangat rentan dilakukan modifikasi dan menghilangkan data yang ada serta mudah dikontaminasi oleh data yang baru dan sensitif terhadap waktu sehingga dibutuhkan sebuah kerangka kerja ilmiah untuk proses investigasi. Hasil penelitian ini berupa alat bukti digital kamera CCTV yang memiliki file rekaman video dan metadata yang merepresentasikan informasi terkait yang didapat dari rekaman kamera CCTV sebagai alat bukti digital yang sah dalam persidangan, dengan merapkan ilmu digital forensik investigasi analisis rekaman kamera CCTV dapat dijaga integritasnya dari sejak pertama ditemukan hingga dijadikan alat bukti digital yang dapat dipertanggungjawabkan dalam persidangan.

\section{Metode Penelitian}

Tahapan penelitian yang dilakukan adalah menggunakan pendekatan metodologi teknik live forensik, metodologi live forensik merupakan pengambilan (capturing) terhadap objek komponen komputasi guna eksplorasi bukti digital dan artefak lainnya dalam keadaan pemrosesan aktif pada bukti digital rekaman kamera CCTV dengan berdasarkan pedoman dan 
persyaratan dalam Standar Nasional Indonesia (SNI) 27037:2014 [12] menggunakan acuan kerangka kerja Common Phases of Computer Forensics Investigation Models.

\subsection{Common Phases of Computer Forensics Investigation Models}

Common Phases of Computer Forensics Investigation Models merupakan kerangka kerja ilmiah yang memiliki dasar dan terbukti untuk proses investigasi digital foresik yang meliputi Acquisition, Identification, Evaluation dan Admission dari bukti yang berasal dari sumber digital dari tempat perkara dan alat yang telah dilakukannya simulasi skenario rekaman kamera CCTV pada suatu peristiwa kasus yang melanggar hukum teknologi informasi dan mengandung pidana, atau membantu untuk mengantisipasi tindakan yang merusak keaslian barang bukti sehingga membuat barang bukti yang telah didapatkan menjadi tidak sah di mata hukum. Kerangka [13] kerja Common Phases of Computer Forensics Investigation Models yang dipakai dalam penelitian dapat dilihat pada gambar dibawah ini:

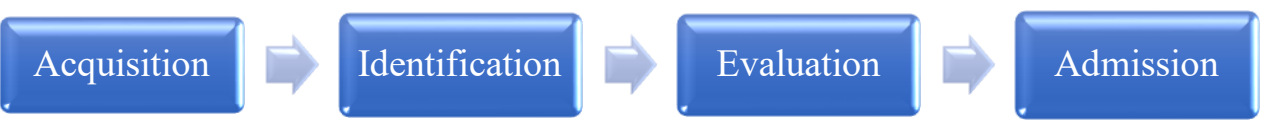

Gambar 1. Alur Tahap Kerangka Kerja

Secara lengkap dipaparkan sebagai berikut: Tahap Acquisition merupakan proses untuk membuat salinan barang bukti digital dan mendokumentasikan metodologi yang digunakan serta aktifitas yang dilakukan dari bukti yang berasal dari sumber digital dari tempat perkara. Tahap Identification melibatkan proses mencari bukti potensial dari perangakat digital dan media penyimpanan digital. Tahap Evaluaiton dilakukan untuk menentukan alat bukti yang sedang diidentifikasi relevan dengan kasus yang sedang diselidiki dengan meneliti yang dilakukan setelah mendapatkan file atau data digital yang diinginkan dari proses pemeriksaan sebelumnya, selanjutnya data tersebut dianalisis secara detail dan komprehensif dengan metode yang dibenarkan secara teknik dan hukum untuk dapat membuktikan data tersebut. Tahap Admission ini menyajikan laporan yang di ekstrak secara detail saat penyelidikan dengan bukti yang telah dianalisis.

\subsection{Simulasi Kasus}

Merupakan tahap dilakukannya simulasi kasus yang ditangkap oleh kamrea CCTV. Simulasi kasus bertujuan untuk melakukan pengujian hasil rekaman kamera CCTV untuk mendapatkan hasil metada rekaman CCTV. Pada simulasi ini dilakukan skenario pada sebuah rumah yang dipasangkan kamera CCTV dengan sudut titik rumah bagian belakang. Pada gambar 2 telihat letak sudut pemasangan kamera CCTV yang dipasang untuk melakukan skenario simulasi kasus.

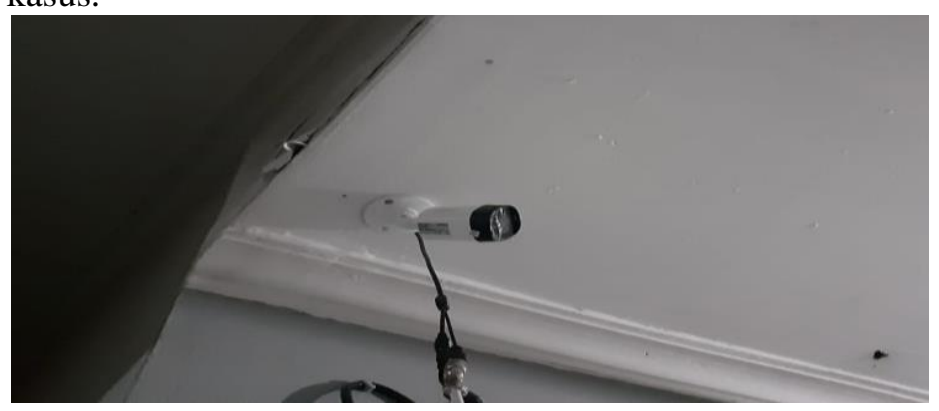

Gambar 2. Letak Posisi Kamera CCTV

\section{Hasil dan Pembahasan}

\subsection{Hasil}

\subsubsection{Acquisition}

Proses akuisisi (Acquisition) melibatkan pembuatan salinan bukti digital dan mendokumentasikan metode live forensik setelah melakuan skenario kasus yang digunakan dan aktivitas yang dilakukan dengan cara logical aquisition, yaitu hanya menargetkan tipe data tertentu, direktori atau lokasi yang diinginkan untuk memperoleh informasi dari alat digital dan 
media peralatan. Seperti pada gambar 3 proses akusisi rekaman kamera CCTV dilakukan setelah melakukan skenario dengan mengcopy file tipe data [14] yang sudah ditentukan.

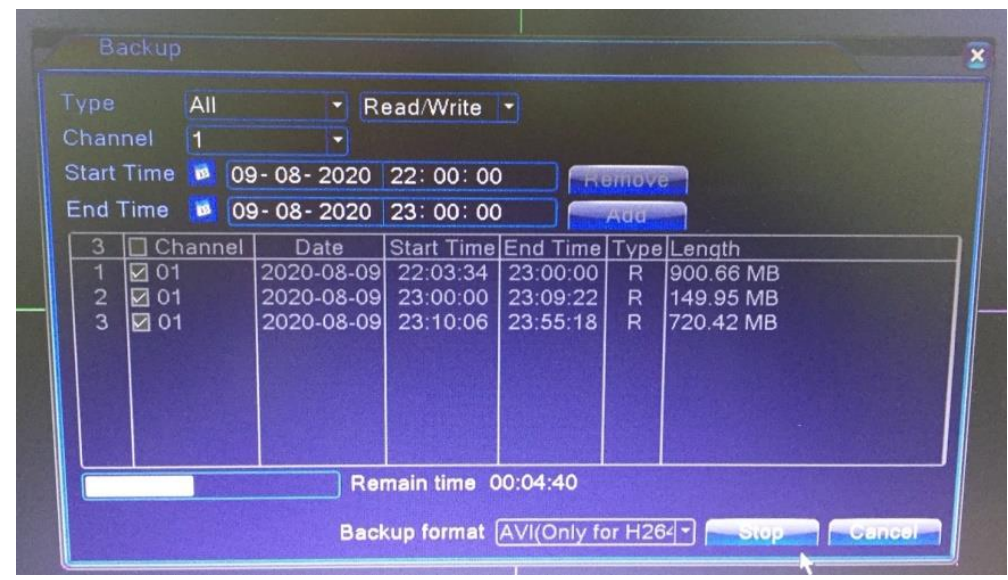

\subsubsection{Identification}

Gambar 3. Proses Acquisition

Investigasi forensik pada tahap identifikasi dimulai dengan pencarian bukti seputar alat rekam yang ada pada kamera CCTV yang difungsikan untuk menyimpan tangkapan gambar yang berasal dari kamera CCTV tersebut dengan mengetahui posisi kamera dan tipe kamera yang dipakai dengan mencantumkan label pada alat bukti digital. Label alat bukti digital diperoleh sebuah rekaman kamera CCTV dengan jenis kamera yang digunakan berupa alat rekam berjenis Stand Alone dengan serial number yang didapat pada tabel 1 tipe kamer.

Tabel 1. Tipe Kamera CCTV

\begin{tabular}{cc}
\hline Tipe & Keterangan \\
\hline Jenis & Stand Alone DVR \\
Merek & HD Hybrid AHD DVR \\
Serial Number & 221C10F3087C1924
\end{tabular}

Dari tabel diatas kamera CCTV memiliki model Stand Alone DVR yang merupakan jenis alat elektronik untuk merekam sebuah video kedalam bentuk format digital dengan media penyimpanan berupa HDD, USB FlashDisk, SSD maupun kartu memori SD. Jenis DVR Stand Alone merupakan jenis DVR yang dapat berdiri sendiri tanpa menggunakan PC (Personal Computer). Pada kamera CCTV DVR biasanya memiliki kemampuan dalam merekam dengan format beresolusi Half D1, CIF, D1, dan 960H dengan ukuran resolusi pada tabel 2 dibawah ini:

Tabel 2. Resolusi Kamera DVR

\begin{tabular}{ccc}
\hline Ukuran & Resolusi (NTSC) & Resolusi (PAL) \\
\hline QCIF & $176 \times 120$ & $176 \times 144$ \\
CIF & $352 \times 240$ & $352 \times 288$ \\
Half D1 & $352 \times 480$ & $352 \times 576$ \\
D1/4CIF & $704 \times 480$ & $704 \times 576$ \\
960H & $928 \times 480$ & $960 \times 576$ \\
\hline
\end{tabular}

Kamera CCTV tipe DVR, yang memiliki fungsi utama alat perekam dengan bantuan kamera sebagai objek rekam dapat dipakai sebagai komputer server, smartphone maupun laptop untuk dapat mengakses kamera CCTV untuk dapat melihat hasil rekaman. Dengan demikian DVR memiliki sebuah MAC Address khusus [15] beberapa port ethernet agar dapat dikoneksikan ke dalam infrastruktur network.

\subsubsection{Evaluation}

Proses evaluation dilakukan untuk menentukan alat bukti yang sedang diidentifikasi relevan dengan kasus yang sedang diselidiki. Forensik digital yang merupakan proses penyelidikan untuk mencari penemuan, mengumpulkan dan menganalisis bukti digital. Dalam 
hal ini bukti digital dalam bentuk rekaman video kamera CCTV. Rekaman tersebut diperiksa sehubungan dengan kegiatan pelaku tindak kejahatan [16] yang telah direkam dalam kamera pengawas pada sebuah rumah. Rekaman tersebut kemudian dilakukan proses tempering video forensik yang digunakan untuk mendapatkan informasi yang dicari.

Selanjutnya file rekaman akan dicari nilai hash verification yang terdapat dalam metadata rekaman CCTV. Hasil nilai hash dapat menjelaskan karakteristik metadata dari hasil rekaman video CCTV untuk membuktikan tingkat keasliannya [17], nilai hash menggunakan algotima tertentu contohnya SHA1, SHA256, MD5 dan lainya sehingga dihasilkan suatu deret nilai yang unik yang berbeda dengan yang lain.

Keutuhan barang bukti video rekaman CCTV didapatkan dari nilai hash yang berfungsi menjelaskan originalitas barang bukti sebagai langkah awal untuk memverifikasi kesesuaian file yang asli dengan file yang dianalisis. Pada gambar 4 merupakan langkah untuk mendaptakan nilai Hash investigasi digital forensik dari alat bukti kamera CCTV.

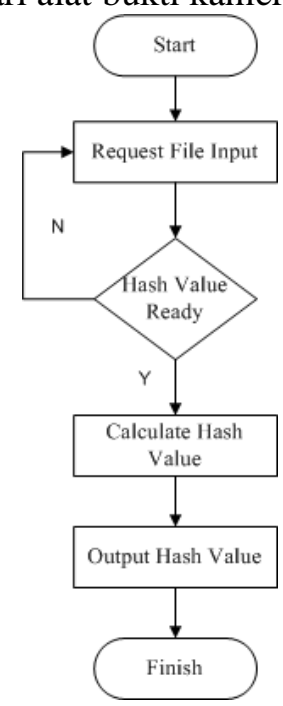

Gambar 4. Autentication Hash Value

Dari file rekaman di dapat nilai Hash dengan ekstensi MD5 (Message Digest algorithm 5) dengan panjang 32 karakter, dibawah ini merupakan gambar 5 hasil nilai Hash video kamera CCTV.

\section{db3197120b42015f157a40a7601c62a9}

\section{Gambar 5. Hash Value}

Setelah mendapatkan nilai hash selanjutnya ialah melakukan analisis terhadap file rekaman kamera CCTV, pada rekaman kamera CCTV didapatkan nformasi sepuran alat rekam dan jenis DVR yang digunakan adalah jenis Stand Alone dengan versi alat rekam pada tabel 3.

Tabel 3. Informasi Alat Rekam

\begin{tabular}{cc}
\hline Info & Versi \\
\hline System & V4.03.R11E4831191.10001.231900.00000 \\
Device Info & 00009.00000.0000000000 \\
Build Date & $19-11-201816: 41: 05$ \\
Mac Address & $0012414 \mathrm{bd} 237$ \\
Serial Number & $221 \mathrm{C} 10 \mathrm{~F} 2087 \mathrm{C} 1924$ \\
Record Channel & 4 \\
Status & 3 \\
Nat Status & Probing DNS \\
Nat Status Code & $0: / 0 /+000$ \\
\hline
\end{tabular}


Informasi alat rekam dengan jenis Stand Alone DVR merupakan jenis perangkat dalam bentuk elektronik yang memiliki tugas untuk merekam video dalam mengubah format digital ke media penyimpanan berupa HDD. Setelah mendapatkan informasi identifikasi tipe kamera selanjutnya mencari informasi terkait fitur CCTV yang terpasang pada DVR seperti multiplexer, network capabilities dan fitur atau alat lainnya yang disandingkan dengan DVR. Berikut adalah tabel 4 yang menjelaskan fitur CCTV.

Tabel 4. Informasi Fitur CCTV

\begin{tabular}{cc}
\hline Fitur & Keterangan \\
\hline Multiplexer & 4 Channel \\
Network Terhubung & Tidak Terhubung \\
Transactional Data & USB \\
Penyimpanan & HDD 500 GB \\
\hline
\end{tabular}

Selanjutnya, setelah identifikasi informasi seputar alat rekam ialah dengan menganalisis file rekaman yang didapat dari kamera CCTV, pada file kamera CCTV terdapat sebuah metadata yang menjelaskan gambaran suatu informasi terstruktur yang dihasilkan dari data rekaman kamera untuk menjelaskan dan menempatkan serta mengelola sebuah sumber data agar dapat dipahami informasi yang terdapat pada file rekaman.

Pengujian file rekaman dilakukan dengan menngunakan tool forensik MediaInfo dan Exif tool dengan tujuan untuk mendapatkan informasi data yang didapat dari header, isi dan footer [16]. Header berada pada banyak byte pertama sebelum informasi isi file, sedangkan footer berada pada beberapa byte yang teletak terakhir sebelum adanya isi informasi. Metadata pada bagian header video kamera CCTV berisikan file signature data yang digunakan untuk mengidentifikasi memverivikasi isi dari sebuah file yang berisikan metadata tentang informasi umum, codec video dan codec audio. Gambar 6 menjelaskan tentang alur pengujian metadata rekaman kamera CCTV untuk memperoleh info terkait integritas alat bukti rekaman video CCTV.

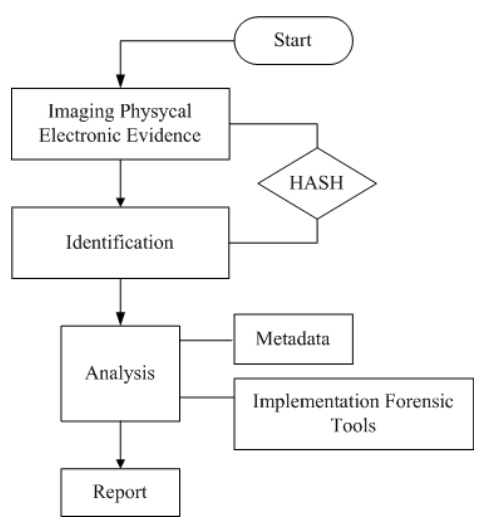

Gambar 6. Core Acquisition

Hasil ekstraksi pengujian metadata menggunakan tool forensik MediaInfo mendapatkan informasi umum terkait data-data pada gambar 7 tentang file nama dengan hasil 1_01_R_09082020231900.avi dengan format .AVI (Audio Video Interleave), berukuran file 238 $\mathrm{MiB}$ dengan durasi 14 menit 50 detik dan memiliki overall bit rate $2244 \mathrm{~kb} / \mathrm{s}$.

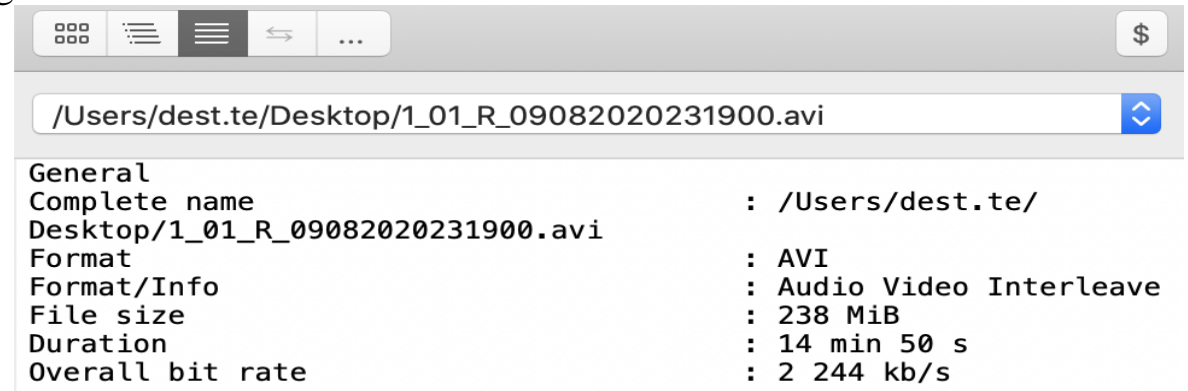

Gambar 7. Informasi Header Metadata 
Setelah didapat tentang informasi umum selanjutnya mendapatkan kompresi video berisikan codec dengan format AVC serta panjangnya video x lebar video yang beresolusi 944 pixels yang memiliki frame rate 22.000 FPS dan ukuran stream yang didapat berupa informasi isi dalam gambar 8:

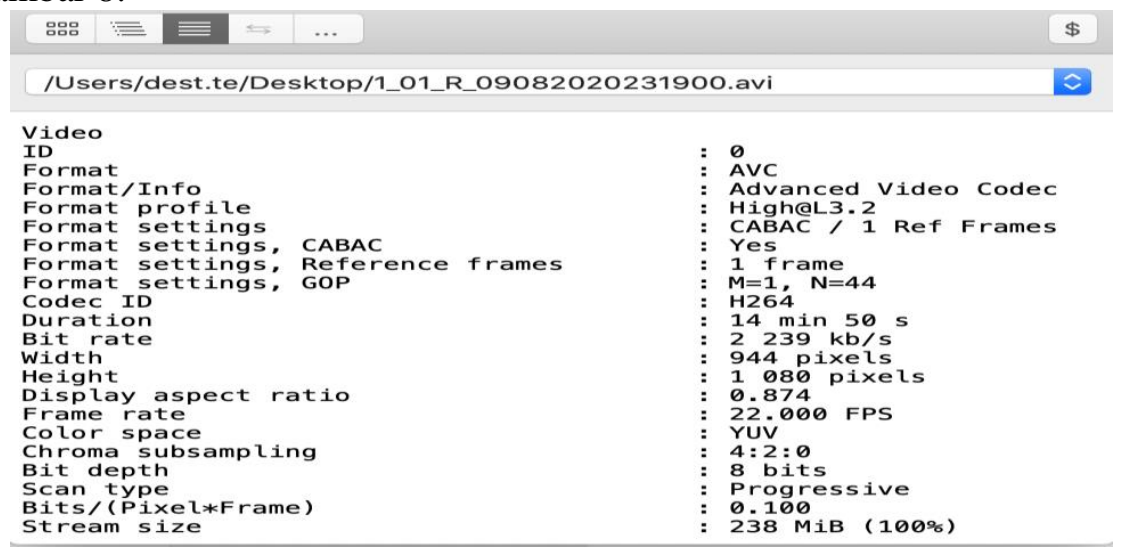

Gambar 8. Informasi Isi Metadata

Forensik rekaman kamera CCTV didapatkan informasi dari gambar 7 tentang codec audio yang berisikan format codec yang menerjemakan biner kedalam pixel untuk menerjemahkan data visual berupa format AVC (advanced Video Codec).

Setelah mendapatkan informasi metadata terkait codec video ialah tentang codec audio yang berisi format codec (compression/decompression), yaitu channel yang dapat menentukan mono maupun stereo untuk rekaman jenis audio dan ukuran stream. Ekstraksi ini mendapkan informasi audio dengan format ADPCM (Adaptive differential pulse-code modulation) yang menjelaskan langkah kualitas data yang diperlukan untuk rasio sinyal terhadap noise atau sinyal-sinyal yang tidak diingkan dalam suatu sistem informasi. Gambar 9 dibawah ini merupakan informasi metadata dari codec audio rekaman kamera CCTV.

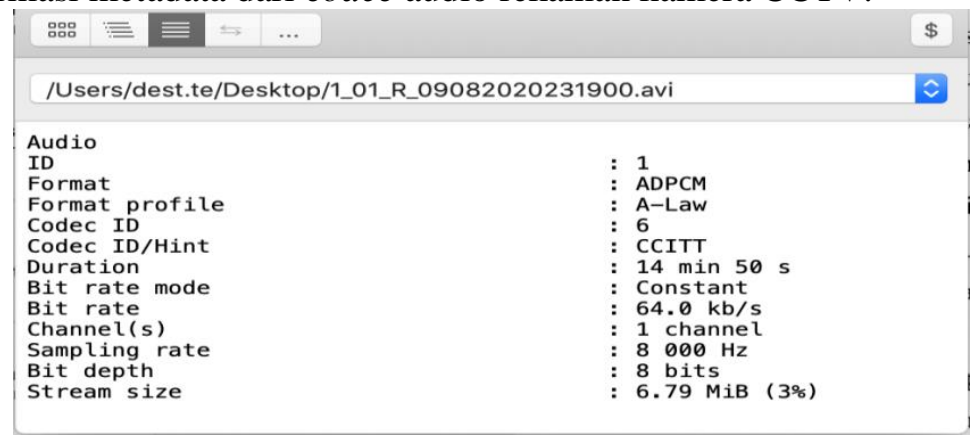

Gambar 9. Informasi Isi Footer

Selain mendapatkan informasi terkait isi dari metadata video, forensik metadata rekaman kamera CCTV didapatkan informasi live data [18] menggunakan Exif Tool yang berupa informasi timestamps [19] tentang catatan waktu terhadapap file metadata video kamera CCTV seperti kapan waktu kejadian sebuah file tersebut dibuat, kapan waktu terakhir file rekaman terjadi proses modifikasi yang terekam pada sistem. Catatan berisikan waktu file tersebut didapat sesuai waktu yang tercatat dengan hasil yang dapat di berupa:

\begin{tabular}{|c|c|}
\hline O & st.te - -bash \\
\hline File Name & : 1_01_R_09082020231900.avi \\
\hline Directory & $:$ /Users/dest.te/Desktop \\
\hline File Size & : $238 \mathrm{MB}$ \\
\hline File Modification Date/Time & : 2020:08:09 23:38:02+07:00 \\
\hline File Access Date/Time & : 2020:10:03 $20: 52: 52+07: 00$ \\
\hline File Inode Change Date/Time & : 2020:10:05 $16: 06: 46+07: 00$ \\
\hline
\end{tabular}

Gambar 10. Informasi Timestamps File 
Pada gambar 10 diatas didapatkan informasi created date 09-08-2020 pukul 09:38:03 dengan keterangan informasi waktu kejadian ketika sebuah file pertama dibuat oleh sistem. Selanjutnya didapatkan informasi tentang modified date 09-08-2020 pukul 23:38:02+07:00 dengan keterangan waktu berdasarkan file tersebut dimodifikasi, dan informasi access date 1008-2020 pukul 13:05:23+07:00 dengan keterangan catatan ketika sebuah file dibaca atau diakses didalam sebuah sistem.

Informasi lain dari metadata file video hasil rekaman CCTV terlihat oknum saat melakukan kegiatan berupa kronolosi isi video yang terekam pada gambar 11 yang tertangkap oleh kamera.

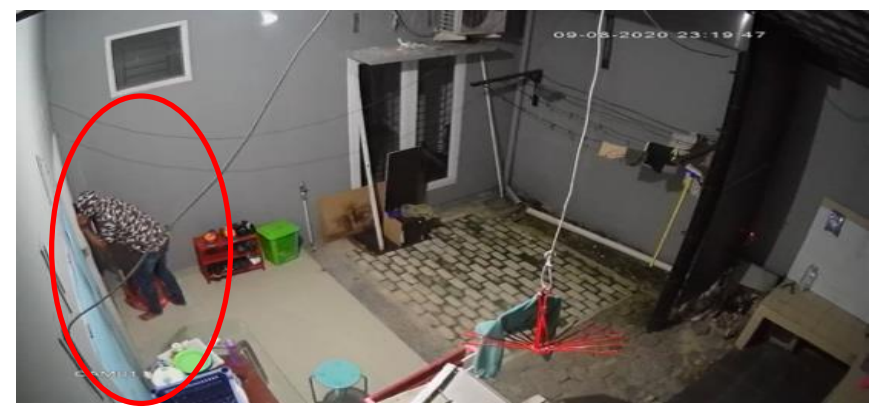

Gambar 11. Isi Kronologi Kejadian

Setelah selesai menguji dan analisis metadata rekaman CCTV teknik investigasi pencarian bukti digital ialah menguji kembali file rekaman untuk memastikan nilainya tidak berubah dari awal di temukan hingga sampai akhir di analisis. Pengujian Hash metadata setelah proses analisis investigasi berhasil maka dilakukan langkah auntetification Hash value dengan langkah pada gambar 4 berupa file rekaman video kamera CCTV setelah dilakukan analisis dan pengujian dapatkan nilai dengan panjang 32 karakter dan berekstensi MD5 dengan nilai db3197120b42015f157a40a7601c62a9 yang menunjukkan nilai Hash yang sama dengan pengujian nilai hash sebelum dilakukan analisis, dengan demikian alat bukti dari rekaman video kamera CCTV tidak mengalami perubahan dengan file aslinya.

\subsubsection{Admission}

Tahap ini menyajikan laporan yang di ekstrak secara detail saat penyelidikan dengan bukti yang telah dianalisa dan dapat dipertanggung jawabkan di pengadilan. Dari hasil pengujian dan analisis metadata rekaman CCTV mendapatkan bukti digital informasi terkait metadata yang di dapat dari hasil rekaman video kamera CCTV telah berhasil untuk menjaga dan memastikan integritas bukti digital dan prosedur pendokumentasian bukti secara kronologis dapat dipergunakan didalam persidangan sebagai alat bukti digital yang sah, tabel 5 merupakan hasil laporan catatan analisis metadata pada rekaman CCTV berupa:

Tabel 5. Hasil Analsis Metadata

\begin{tabular}{ccc}
\hline No. & Identifikasi & Keterangan \\
\hline 1 & Seputar Tipe Alat Rekam & CCTV Stand Alone DVR \\
& Compresor Name \\
& Handler Description \\
2. & Info File & Waktu keajdian dalam file 2020:08:09 \\
& & Nama Rekaman 1_01_R09082020239000.avi \\
& & Format File MP4 \\
& & Video/x-msvideo \\
& & Durasi 0:14:50 \\
3. & Serial Number & 221C10F2087C1924 \\
4. & Record Channel & Channel 4 \\
5. & Kualitas Video & Default \\
\hline
\end{tabular}




\begin{tabular}{ccc} 
No. & Identifikasi & Keterangan \\
\hline 6. & Frame Rate & $124.5 \mathrm{~KB} / \mathrm{S}$ \\
7. & Frame Record Size & Width $\mathrm{x}$ Height $=944 \times 1080$ \\
8. & Kapasitas & $238 \mathrm{MB}$ \\
9. & Firmware & Probing DNS code $0: / 0 /+000$ \\
10. & Timestamps & Date/time Actual 09:08:2020 Pukul \\
& & $23: 38: 02+07: 00$ \\
\hline
\end{tabular}

Menuru [20], model pelaku dalam interaksi proses chain of custody akan dipengaruhi oleh ketentuan hukum disetiap negara. Namun apapun model yang dibangun harus dapat menjelaskan aktivitas, hubungan dan keterlibatan pelaku pada bukti digital. Sebagai contoh dalam perkara nomor 85/PID/.B/2012/PN.PWT yang dikutip dari penelitian [21] didapat alat bukti elektronik berjenis 3 buah CD pada rekaman kamera CCTV yang tidak memiliki keuatan hukum disebabkan tidak diajukan atau disertakannya alatu bukti berupa surat yang menyatakan hasil dari proses hashing dan penerimaan barang bukti kedalam bentuk dokumen surat sebagai lampiran bentuk keasilian suatu file yang sedang di investigasi , hal demikian dapat memberikan petunjuk kepada pihak pengadilan tidak dapat menerima bukti yang diberikan apabila suatu tindak pidana yang terekam oleh kamera tidak dapat menunjukkan dan memastikan bagaimana barang bukti yang sedang ditangani.

Dari perkara yang ada Chain of Custody digunakan untuk "A Road Map That Shows how evidence was collected, analyzed and preserved in order to presented as evidence in court". Pada gambar 10 menunjukkan formulir Chain of Custody yang didapat dari metadata rekaman CCTV dapat digunakan saat persidangan dengan hasil bukti yang diserahkan sudah sesuai dan meluui proses investigasi digital forensik telah terdokumentasi dengan melampirkan bukti tidak adanya unsur barang bukti yang diserahkan telah dimanipulasi. Dengan demikian laporan hasil investigasi metadata kamera CCTV didapatkan pada gambar 10 yang akan digunakan dalam persidangan.

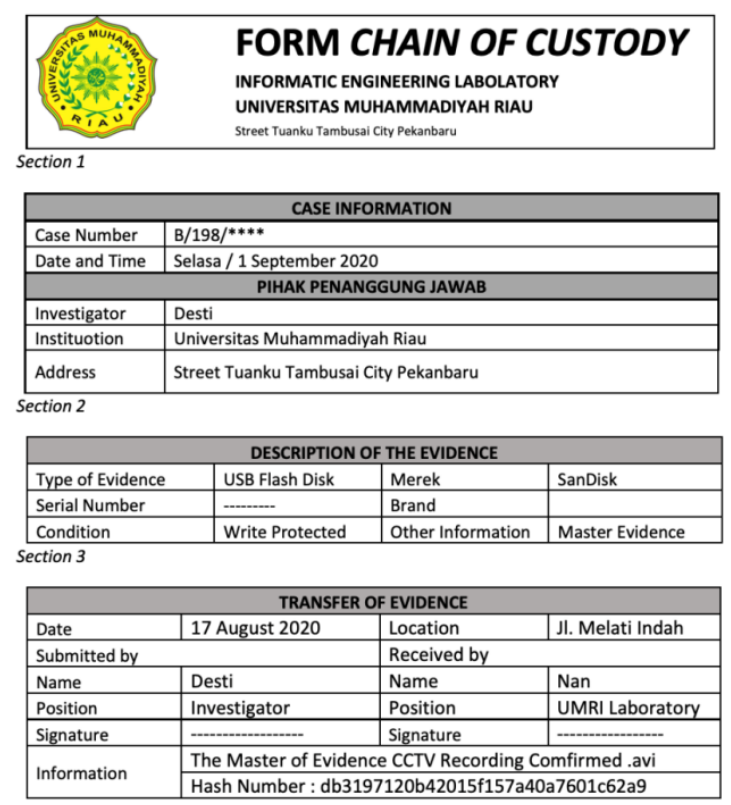

\subsection{Pembahasan}

Gambar 10. Dokumen Chain of Custody

Menangani bukti digital atau bukti elektronik yang terkait dengan kamera CCTV semakin komplek, oleh karena itu metode yang digunakan dalam menangani CCTV harus sesuai dengan keadaan dimana alat bukti tersebut didapatkan, pada penelitian sebelumnya telah membahas framework akuisisi terkait jenis kamera CCTV berupa tipe Analog DVR (Digital Video 
Recorder), tipe NVR (Network Video Recorder) dan NVR Based on Cloud Computing, akan tetapi dalam penelitian [22] metode akuisisi yang dilakukan belum mengkaji status live atau static forensik, dimana live forensik mengambil (capturing) terhadap objek komponen komputasi guna eksplorasi bukti digital dan artefak lainnya dalam keadaan pemrosesan aktif pada bukti digital, sedangkan pada static forensik bukti digital yang akan dieksplore diambil dalam keadaan komputer mati dan bisa diartikan investigator melakukan capturing pada komponen penyimpanan secara tidak langsung, hal yang potensial terjadi pada metode static forensik adalah manipulasi data hasil akuisisi, hal ini dibenarkan pada perspektif investigator dalam rangka membuktikan artefak-artefak yang perlu diperjelas secara mekanisme dan fakta.

Pada penelitian ini bukti digital yang di capture dilakukan secara realtime yang mengindikasikan penelitian ini menggunakan live forensik. Barang bukti pada penelitian ini dapat dipastikan tidak terdapat manipulasi dan terbukti dari nilai Hash yang identik pada saat perhitungannya dalam dua garis waktu yang berbeda (alat bukti sebelum dianalisis dan yang sudah dianalaisis). Pada gambar 11 ditampilkan secara visual hasil dari analisisis metadata oleh sistem yang menjadi tantangan bagi investigator dalam melakukan analisa khususunya dalam karakteristik barang bukti fisik (kamera CCTV) serta bukti digital berupa rekaman video masih terjaga integritasnya dengan membuktikan jumlah frame dan durasi waktu yang sama seperti saat dilakukan pengujian, yaitu selama 14 menit 50 detik.

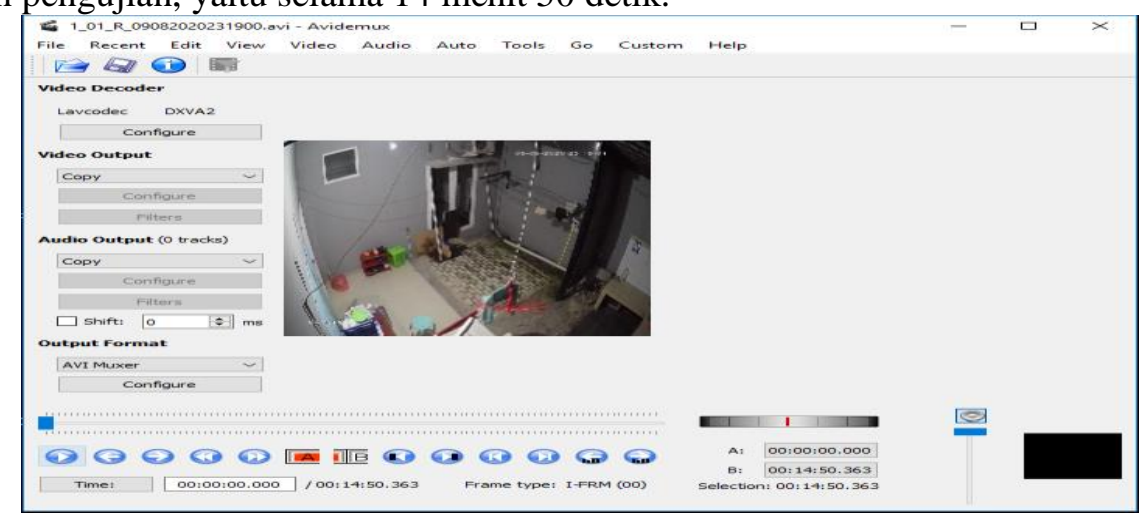

Gambar 11. Raw Image

\section{Kesimpulan}

Tahapan utama akuisisi dalam investigasi dan analisis forensik digital diperlukan integritas keaslian barang bukti dari saat ditemukan, diperoleh, dianalisis hingga tahap pelaporan sesuai dengan prinsip Chain of Custody. Secara teknis keutuhan dan keaslian barang bukti dapat dibuktikan dengan menghitung nilai hash, sedangkan dalam hal alat bukti berupa CCTV dibutuhkan kemampuan untuk menggunakan aspek multimedia dalam menganalisis alat bukti digital metadata rekaman kamera CCTV yang digunakan untuk memperkuat alat bukti digital dalam persidangan.

\section{Daftar Pustaka}

[1] G. Hendita, A. Kusuma, and I. N. Prawiranegara, "Analisa Digital Forensik Rekaman Video CCTV dengan Menggunakan Metadata dan Hash," Pros. Semin. Nas. Sist. Inf. dan Teknol., vol. 3, no. 1, pp. 223-227, 2019.

[2] E. Casey, "Interrelations between digital investigation and forensic science," Digit. Investig., vol. 28, pp. A1-A2, 2019, doi: 10.1016/j.diin.2019.03.008.

[3] M. N. Al Azhar, Praktical Guidlines for Computer Investigation. 2529.

[4] R. A. Ramadhan, Y. Prayudi, and B. Sugiantoro, "Implementasi dan Analisis Forensika Digital Pada Fitur Trim Solid State Drive (SSD)," Teknomatika, vol. 9, no. 2, pp. 1-13, 2017, [Online]. Available: http://teknomatika.stmikayani.ac.id/wpcontent/uploads/2017/07/1.pdf.

[5] W. Pranoto, I. RIadi, and Y. Prayudi, "Live forensics method for acquisition on the Solid 
State Drive (SSD) NVMe TRIM function," Kinet. Game Technol. Inf. Syst. Comput. Network, Comput. Electron. Control, vol. 5, no. 2, pp. 129-138, 2020, doi: 10.22219/kinetik.v5i2.1032.

[6] D. Mualfah and I. Riadi, "Network Forensics For Detecting Flooding Attack On Web Server," IJCSIS) Int. J. Comput. Sci. Inf. Secur., vol. 15, no. 2, 2017.

[7] W. Abraham, H. Firmansyah, and W. Abraham, "Analisis Pembuktian Alat Bukti Closed Circuit Television ( CCTV ) Sebagai Alat Bukti Petunjuk," no. 11, 2019.

[8] A. Yudhana, I. Riadi, and I. Zuhriyanto, "Menggunakan Metode Digital Forensics Research Workshop ( DFRWS )," vol. 20, no. 2, pp. 125-130, 2019.

[9] M. Subli, B. Sugiantoro, and Y. Prayudi, "Metadata Forensik untuk Mendukung Proses Investigasi Digital," J. Ilm. DASI, vol. 18, no. 1, pp. 44-50, 2017, doi: 10.13140/RG.2.2.34035.94242.

[10] M. N. O. Sadiku, A. E. Shadare, and S. M. Musa, "Digital Chain of Custody," Int. J. Adv. Res. Comput. Sci. Softw. Eng., vol. 7, no. 7, p. 117, 2017, doi: 10.23956/ijarcsse.v7i7.109.

[11] C. Liu, S. G. Li, S. Qin, and S. G. Yang, "Research and application of influences of lateral pressure coefficients on the extension angle of coal cracks," Math. Probl. Eng., vol. 2016, no. 3, pp. 17-31, 2016, doi: 10.1155/2016/3068347.

[12] D. M. Suratno, I. Riadi, and Y. Prayudi, "First Respond Framework Untuk Forensik CCTV," Hacking Digit. Forensics Expo., pp. 13-20, 2018.

[13] C. Paper, Y. Prayudi, and U. Islam, "( DiFRI ) Untuk Mengukur Tungkat Kesiapan Institusi Dalam Menanggulangi Aktifitas Model Digital Forensic Readiness Index (DiFRI )," no. July, 2016.

[14] A. Putra Justicia, "Analysis of Forensic Video in Storage Data Using Tampering Method," Int. J. Cyber-Security Digit. Forensics, vol. 7, no. 3, pp. 328-335, 2018, doi: 10.17781/p002471.

[15] D. Mualfah, Y. Fatma, and R. A. Ramadhan, "Anti-forensics: The image asymmetry key and single layer perceptron for digital data security," J. Phys. Conf. Ser., vol. 1517, no. 1, 2020, doi: 10.1088/1742-6596/1517/1/012106.

[16] X. Du, N. A. Le-Khac, and M. Scanlon, "Evaluation of digital forensic process models with respect to digital forensics as a service," Eur. Conf. Inf. Warf. Secur. ECCWS, pp. 573-581, 2017.

[17] H. A. Rahman, "Otentikasi File Dengan Algoritma Kriptografi SHA-1 Menggunakan Python Dan Pycrypto," no. January 2013, 2008.

[18] R. Chowdhry, "FORENSIC SCIENCE PAPER No . 7 : Criminalistics and Crime Scene Investigation MODULE No . 32: Use of CCTV for Forensic Evidence FORENSIC SCIENCE PAPER No . 7 : Criminalistics and Crime Scene Investigation MODULE No . 32 : Use of CCTV for Forensic Evidence," no. 7.

[19] R. Alshalawi and T. Alghamdi, "Forensic tool for wireless surveillance camera," Int. Conf. Adv. Commun. Technol. ICACT, no. January 2017, pp. 536-540, 2017, doi: 10.23919/ICACT.2017.7890148.

[20] J. Hukum and K. Ummah, "Peran Laboratorium Forensik Polri Sebagai Pendukung Penyidikan Secara Ilmiah Dalam Sistem Peradilan Pidana Di Indonesia Teguh Prihmono *, Umar Ma'ruf **, Sri Endah Wahyuningsih *** *," J. Huk. Khaira Ummah, vol. 13, no. 1, pp. 273-286, 2018.

[21] S. Terintegrasi and K. D. A. N. Berkesinambungan, "Linguistik Forensik: Sumbangsih Kajian Bahasa dalam Penegakan HUKUM," vol. 1, no. 3, pp. 51-60, 2019.

[22] D. Hariyadi, F. E. Nastiti, and F. N. Aini, "Framework for Acquisition of CCTV Evidence Based on ACPO and SNI ISO / IEC 27037 : 2014," Int. Conf. Informatics Dev., 2018. 